EECCIÓN: Teorías geográficas, geografía de la

cultura y la vida cotidiana
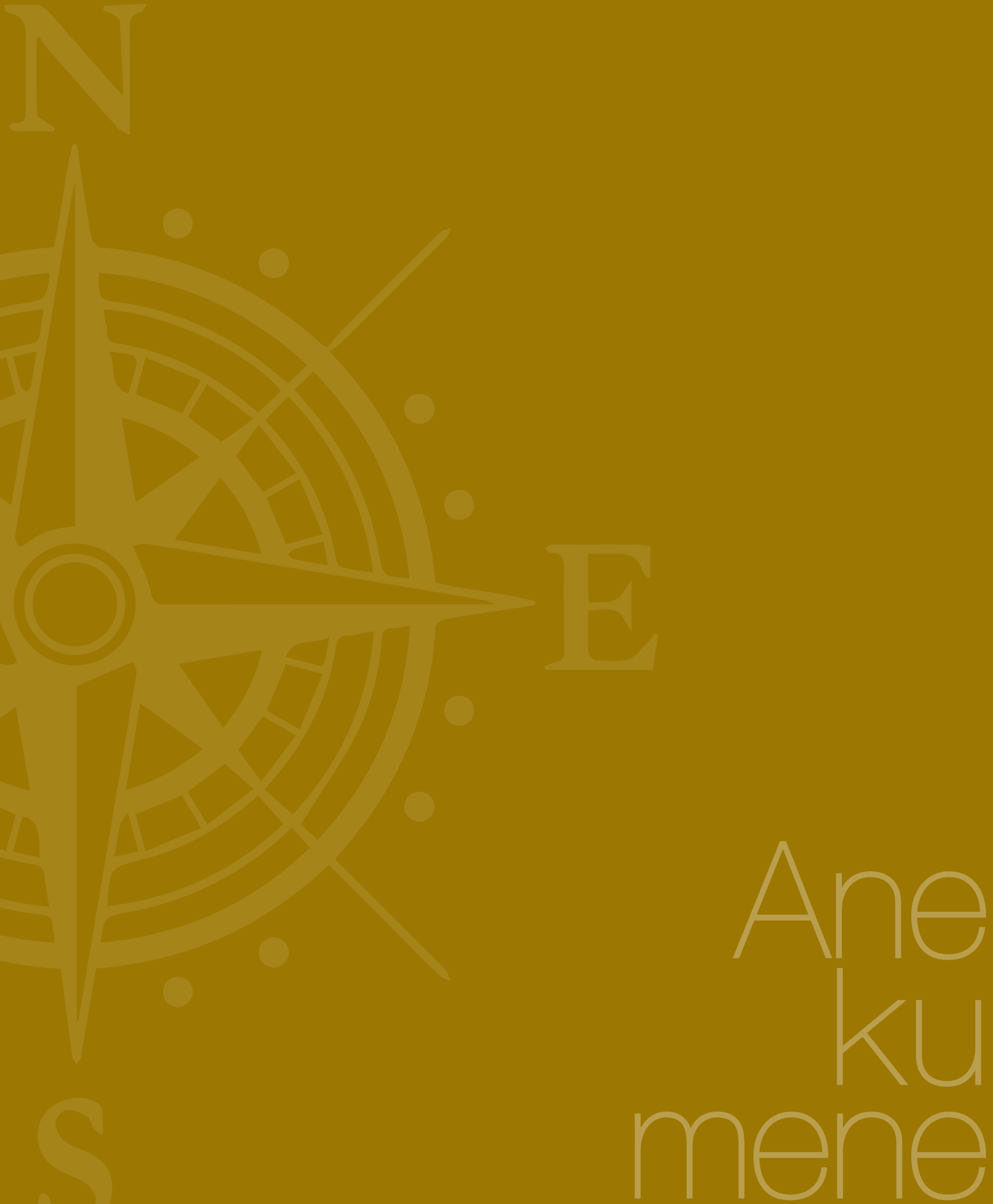


\section{Vidas secas: a paisagem na literatura e na geografia}

\section{Vidas secas: el paisaje en la literatura y la geografía Barren Lives: Landscapes in Literature and Geography}

Cláudia Eliane Ilgenfritz Toso*

Maristela Maria de Moraes ${ }^{* *}$

Helena Copetti Callai**

\section{Resumo}

Este texto apresenta reflexão sobre geografia e literatura considerando como categoria de análise a paisagem e os conceitos de espaço, tempo e lugar como ferramentas intelectuais para aprendizagens que tenham sentido para os alunos que frequentam o Ensino Médio. Para tanto, apresentamos análise e interpretação de fragmentos da obra Vidas Secas, de Graciliano Ramos, articulados aos conceitos de paisagem, espaço, tempo e lugar. $O$ objetivo é verificar a possibilidade de um ensino que oportunize a realização de aprendizagens que tenham sentido partindo da premissa de que os alunos possuem diferentes concepções e entendimentos sobre os mais diversos temas, principalmente quando se refere ao lugar. Assim, apresentamos neste texto uma possibilidade de percurso metodológico interdisciplinar desenvolvido com alunos de Ensino Médio em que foram considerados elementos como observação, descrição, interpretação e compreensão. Orientam teoricamente este artigo autores como: Marques (1990, 2000), Santos (1998), Callai (1996) e Hermann (2002), dentre outros.

\section{Palavras-chave}

paisagem; espaço e tempo; lugar; geografia e literatura.

\footnotetext{
* Universidade Regional do Noroeste do Estado do Rio Grande do Sul.

** Universidade Regional do Noroeste do Estado do Rio Grande do Sul.

${ }^{* * *}$ Universidade Regional do Noroeste do Estado do Rio Grande do Sul.
} 


\begin{abstract}
Resumen
Este texto presenta una reflexión sobre la geografía y la literatura considerando como categoría de análisis el paisaje y los conceptos de espacio, tiempo y lugar como herramientas intelectuales de aprendizaje para los alumnos de educación secundaria. Por tanto, presentamos un análisis e interpretación de fragmentos de la obra Vidas Secas, de Graciliano Ramos, articulando junto a ello los conceptos de paisaje, espacio, tiempo y lugar. El objetivo es verificar la posibilidad de una enseñanza que permita la formalización de aprendizajes que tengan sentido, partiendo de la premisa de que los alumnos poseen diferentes conceptos y entendimientos sobre los más diversos temas, principalmente cuando se refiere al lugar. Así, presentamos en este texto un posible recurso metodológico interdisciplinar desarrollado a partir de la observación, descripción, interpretación y comprensión. Orientan teóricamente este artículo autores como Marques (1990, 2000), Santos (1998), Callai (1996) y Hermann (2002), entre otros.
\end{abstract}

\section{Palabras clave}

paisaje; espacio y tiempo; lugar; geografía y literatura.

\section{Keywords}

landscape; space and time; place; geography and literature. 


\section{Introdução}

A proposta deste texto é apresentar a partir de pesquisas que abordam a questão do ensino da geografia através de obras literárias. Para tanto, delimitamos a análise aqui trazida na abordagem de um texto literário do autor brasileiro Graciliano Ramos ${ }^{1}$, na eleição da paisagem como categoria de análise e dos conceitos de espaço, de tempo e de lugar como ferramentas intelectuais no processo de ensino e aprendizagem que cada vez mais tenham sentido para os alunos, podendo assim criar situações que contribuem no processo de formação cidadã. Para tanto, consideramos o lugar, conceito e conteúdo da geografia que ocupam lugar central desta área durante toda a educação básica.

O intuito é buscar a articulação entre o que se produz enquanto ciência e os conhecimentos prévios dos alunos, oportunizando aprendizagens que possam ir para além do senso comum, sem desconsiderar as concepções e entendimentos que já possuem. Para tal, apresentamos neste texto uma possibilidade de percurso metodológico interdisciplinar que considera elementos como observação, descrição, interpretação e compreensão. Para além disso, abordamos questões relativas a obra Vidas Secas; a paisagem como categoria central; os conceitos de espaço e de tempo; o lugar como conceito da geografia e conteúdo da literatura, e por fim, apresentamos os conceitos na obra Vidas Secas de Graciliano Ramos.

\section{A metodologia}

O percurso metodológico que escolhemos, sustenta-se na análise hermenêutica (Hermann, 2002), considerando a observação e descrição, a interpretação, no sentido de elaborar as possibilidades de alternativas, e a compreensão que supõem a tensão entre a estranheza e a familiaridade. Essa análise considera sempre a dimensão histórica, que é a consciência que encaminha para compreender a realidade que sempre tem horizontes abertos e não fechados de modo a encerrar em uma verdade apenas.

A observação e a descrição são realizadas de forma intencional e com elementos metodológicos que as orientam. Os olhares em torno dos objetos e das paisagens são sempre subjetivos, mas partem de um aporte teórico que é científico. É na constante provocação para reflexão que vamos nos posicionando em uma perspectiva hermenêutica de análise. Para que a interpretação seja possível, tanto aluno quanto professor necessitam

\footnotetext{
1 Graciliano Ramos nasce em 27 de outubro de 1892 em Alagoas. Suas primeiras experiências como escritor foram no periódico Echo Vicosense e no jornal carioca O Mulato. No ano de 1932 começa a escrever São Bernardo, romance que publicou em 1934. Em março de 1936 é preso, em Maceió, sem culpa formada, acusado de ser comunista. Segue para o Rio de Janeiro onde fica preso quase um ano. Ainda na prisão publica o romance Angústia. Ao sair da cadeia vai morar com a família no Rio de Janeiro. Inicia a publicação de alguns contos no jornal argentino La prensa, entre eles "Baleid", que fará parte de Vidas Secas, publicado em 1938.
}

de conhecimentos em torno do objeto. Como interpretar quando não se conhece nada sobre o mesmo? É a partir do levantamento dos conhecimentos prévios dos alunos que vamos delineando as possibilidades de análise e compreensão. Na sequência definimos o que será observado e descrito da obra que se está estudando. É fundamental que tenhamos claro que conceitos serão estudados porque estes é que orientarão a leitura da obra.

A intencionalidade deve ser definida para que se tenha um caminho inicial de análise delineado. É a sala de aula o espaço tempo "em que somos um diálogo e que podemos ouvir-nos uns aos outros". (Hölderlin, apud Hermann, 2002). É nela que os alunos vivenciarão enfrentamentos entre suas verdades, as verdades dos outros e as verdades da ciência. E o professor é o provocador nesse processo, pois tem um olhar pedagógico e científico que orientam seu trabalho. Para Mario Osorio Marques (2000)

Não se pode ocupar a docência com a mera transmissão de conhecimentos. Ensinar não é repetir; é reconstruir as aprendizagens. Trata-se de realizar a tradução dos conceitos reconhecidos no estado atual das ciências para o nível das práticas sociais contextualizadas e conjunturais. Traduzir aqui significa realizar uma inversão do plano da idealidade do conhecimento abstrato para o terreno em que firmam os pés as práticas cotidianas e concretas dos sujeitos/atores em presença. (pp.117-118).

O professor ao se posicionar também em uma condição de sujeito aprendente como sugere Paulo Freire, e não somente aquele que ensina, preocupa-se certamente com esse processo de tradução dos conceitos, sem que haja simplificação. É no espaço escolar que os alunos terão condições para se apropriar do conhecimento produzido historicamente. Ao escolhermos realizar um trabalho com base em uma metodologia que articula hermenêutica e teoria crítica, temos claro quem são os sujeitos do processo educativo. Criar condições para que a observação, a descrição e a interpretação aconteçam pode causar desconforto por tirar o professor do centro do processo, mas passa a considerar todos os sujeitos como construtores de conhecimento. É fundamental que o professor possua domínio de sua área específica e das questões teórico metodológicas do trabalho pedagógico, mas ao considerar o conhecimento que o aluno possui auxilia nesse processo.

Desta forma, o trabalho pode ser realizado com alunos do Ensino Médio, que já possuem conhecimentos prévios com relação aos conceitos de paisagem, lugar espaço e tempo. Na sequência o professor apresentará fragmentos da obra Vidas Secas com a intenção de realizar a observação, a descrição, a interpretação destes, buscando articulação com os conceitos. Acreditamos, assim, que é uma possibilidade de aprofundamento conceitual. 


\section{A obra}

A obra "Vidas Secas" é um romance escrito por Graciliano Ramos entre 1937 e 1938 e publicado, originalmente, em 1938. A obra é escrita em terceira pessoa e narra a história de uma família de retirantes do sertão brasileiro que vive em uma condição subumana, diante de problemas sociais como a seca, a pobreza, e a fome, e, em consequência, vive diferentes sentimentos e emoções que os obriga a viver e a procurar meios de sobrevivência, criando, assim, uma ligação muito forte com a situação social vivenciada no Brasil durante todo o século XX. As desigualdades no país permanecem, embora tenham ocorrido mudanças significativas na vida da população. A desigualdade é uma marca forte na história do país, mas as condições de vida hoje apresentam uma pequena melhora. O livro possui treze capítulos até certo ponto autônomos, mas que se ligam pela repetição de alguns motivos e temas tais como a paisagem árida, os pensamentos fragmentados das personagens, a linguagem usada por estes, assim como também as diferenças sociais (Moraes, 2012). A obra é considerada pelos críticos um marco na Literatura brasileira principalmente ao Modernismo brasileiro.

\section{A paisagem como categoria de análise}

A paisagem é o retrato do instantâneo que o espaço apresenta em determinado momento. Nela aparecem os resultados da ação humana, materializados em formas específicas e concretas que se tornam visíveis ou perceptíveis. Mas também mostra a natureza que pode estar intacta ou foi modificada no seu todo ou em determinados aspectos. As paisagens que nós conhecemos sempre têm a marca do homem, pois que de alguma forma já sofreu alterações. Ela é o retrato do espaço que os homens constroem e sendo assim a vista que se tem de uma paisagem congela as relações sociais e a história em determinado momento que o olhar alcança. Mas a paisagem não é apenas o que a vista alcança, esta é a aparência. Ela é muito mais, pois além do domínio do visível, que mostra os volumes, ela é também de cores, movimentos, odores, sons, etc.

Na obra Metamorfoses do espaço habitado (Santos, 1988), considera que a paisagem assume características marcantes que podem ser assim apresentadas: - a paisagem toma escalas diferentes e assoma diversamente aos nossos olhos, pois se olhamos a paisagem do alto de um mirante temos uma perspectiva e se olharmos no mesmo plano de altitude em que ela está temos outra visão e nova possibilidade de interpretação; - a dimensão da paisagem é a dimensão da percepção, o que chega aos sentidos, portanto cada um interpreta e analisa com as suas bases de interpretação; - a percepção é um processo seletivo de apreensão e mesmo a realidade sendo apenas uma, cada pessoa a vê de forma diferenciada, esta seleção pode ser orientada pelo professor, mas cada um sempre terá a interpretação singularizada; - a paisagem artificial é aquela transformada pelo homem e, neste sentido podemos constatar que as paisagens com as quais trabalhamos na aula são todas, ou em sua maior parte artificiais, quer dizer é o espaço natural transformado; - a paisagem natural é aquela que ainda não foi mudada pelo homem e, neste sentido, essas paisagens só podem ser estudadas a partir de intermediação de outros elementos, seja fotografias, seja descrições, literatura, quadros, pinturas; - a paisagem é sempre um conjunto heterogêneo onde se mesclam o artificial e o natural; - a paisagem não se cria de uma só vez, mas por acréscimos, substituições, pois as histórias vão se acumulando no espaço e criando alterações e; - a paisagem é escrita uma sobre a outra, são as heranças de diversos tempos, em determinados lugares isso é possível de ser percebido e identificado; - a paisagem é objeto de mudança, é resultado de muitos tempos acumulados, inclusive algumas mudanças são perceptíveis por vezes de um dia para outro, ou em estações de ano diferentes, mas também por episódios de catástrofes como um terremoto, um tsunami, uma enchente, um vendaval.

Outras mudanças são lentas e difíceis de serem identificadas em curto prazo, mas acontecem e deixam marcas. 0 importante é saber que as mudanças ocorrem e transformam as paisagens e que além dos movimentos da natureza há um conjunto de forças que são sociais envolvendo política, economia, cultura, religião, etc. Estes elementos indicados podem se constituir como o exercício de compreensão do que é o espaço construído pelos homens, tendo claro que é fundamental considerar as escalas de análise na interpretação da paisagem, pois que ela em si expressa e mostra um espaço absoluto, mas que tem relação com o espaço mais amplo, e com o tempo.

Destacamos que para estudar a paisagem são aspectos importantes: 1- observação da paisagem considerando critérios predefinidos em conjunto entre professor e alunos; 2 - interpretação do que é observado mediante: aparência do que é observado; limites do lugar que ocupa a paisagem; 3- descrição do que está no interior desse espaço; 4- contextualização do espaço num espaço mais amplo, considerando os limites e as relações com a vizinhança; 5- levantamento das motivações que levam a configuração dessa paisagem considerando a dimensão de tempo. Podem ser realizadas entrevistas com moradores, busca de documentos, mapas, relatos sobre o lugar; 6- representação da paisagem que pode ser feita através de desenhos, de fotografias, de um texto, de mapas, etc; 7- análise do que é entendido da paisagem e da importância de fazer a análise da mesma.

No caso desta pesquisa expressamos a possibilidade de estudar geografia considerando a literatura, e especificamente a partir da obra antes referida. Para tanto, é fundamental levar em consideração que aquilo que o aluno conhece resulta da sua vivência e que no seu cotidiano eles têm o conhecimento de questões que são abordadas na obra. Consideramos também que na escola ele precisa contextualizar teoricamente a questão para verificar que aquilo que existe e pode ser observado, porque ele conhece não acontece ao acaso. Nem aquilo que este autor apresenta na obra é casualidade. 
Neste sentido, são importantes os conceitos que pode ser desenvolvidos através da realização da atividade. Para Marques (1990), "O conceito é representação instituída idealmente, que, no entanto, constrói-se mediante experiência histórica, em que, por força reguladora da analogia, dá-se a passagem do saber já situado para as possibilidades dos novos conhecimentos" (p. 40). Os conceitos levam ao desenvolvimento do pensamento abstrato que decorre do acesso ao conhecimento que a humanidade produziu ao longo de sua história, e os fundamentos científicos que sustentam as interpretações.

Com relação às características da paisagem e aos aspectos importantes que devem ser considerados ao estudar a paisagem, marcamos o campo teórico desta proposta. Quando apontamos para a paisagem para além do visível, considerando tantas outras características apostamos na possibilidade de realização de um trabalho complexo que acredita no sujeito aluno e no sujeito professor. É romper com a lógica do simples para o complexo. É a forma de olhar para a realidade que não é fragmentada, mas que muitas vezes na escola fragmentamos. Quando consideramos que para estudar a paisagem é preciso realizar os processos de observação, interpretação, descrição, contextualização, configuração, representação e análise pensamos numa das funções da escola que é formação de sujeitos críticos capazes de ler o mundo e protagonizar ações nele e sobre ele. É ser capaz de entender o espaço e tempo a que pertence, mas acima de tudo como estes produzem e são produzidos.

\section{Os conceitos de espaço e de tempo}

O espaço é o objeto da geografia e como tal a ele se reportam todas as discussões e reflexões para fazer a análise geográfica. Entendemos que o conhecimento singular de cada sujeito se dá no contexto social, portanto torna-se necessário balizar o conceito de espaço que sustenta as bases da análise e da possibilidade e abstração e teorização dos conteúdos que são os temas da vida e que a geografia estuda. Para esta reflexão acerca do conceito de espaço, há que se considerar em três dimensões: espaço absoluto, relativo e relacional.

O espaço absoluto é fixo nos limites físicos e de tempo em que se realiza o fenômeno. É o lugar que apresenta limites e características internas próprias que o definem com a especificidade que contem e se explica internamente como tais, mas não possibilita o avanço do que está estritamente registrado ali. 0 espaço relativo mostra a relação entre as coisas, entre os fenômenos que estão contidos no espaço absoluto, mas que estabelecem uma relação com um entorno e também com motivações diferenciadas. Essas se expressam a partir de elementos da natureza e da sociedade. Existe uma relação de cada lugar absoluto com seu entorno que é dado pelos limites que além de cortar-fragmentar o espaço lhe oferece as possibilidades de relação.

O espaço relacional envolve as subjetividades, e como tal é mais difícil de ser apreendido, mas assim mesmo é importante e necessário para a análise espacial que se pretende que seja comprometida com uma sociedade justa. Este nível de espaço não exige a contiguidade físico-espacial, mas tem em si a relação que lhes faz ultrapassar os limites e que os integra de modo a buscar a compreensão da realidade. Tendo em vista que o espaço absoluto contém o relacional e vice-versa, do mesmo modo o espaço relativo contém o absoluto e o relacional (Silva, 1986). Nesta lógica em que se considera a dimensão das escalas de análise abre-se a possibilidade de fazer a abordagem dos fenômenos considerando a complexidade em que se constituem. As paisagens apresentadas na obra literária precisam ser consideradas tendo estas referências do conceito de espaço.

Para discutir o conceito de espaço, para o ensino de geografia, considerando o texto literário, nos apoiamos em Garrido ${ }^{2}$ (2013) que discute os níveis de espaço, que podem ser considerados elementos estruturantes da experiência espacial. Segundo este autor, o espaço concebido é aquele do plano das práticas espaciais que acolhe a vida cotidiana; o espaço percebido é o plano da representação dos espaços e está a indicar o habitus assim como autoriza a verdade em um plano simbólico; o espaço vivido é o plano dos espaços de representação em que se constitui se produz a vida, se constitui no plano dos discursos e do campo imaginário; o espaço reconhecido é o plano dos espaços de identificação recíproca ideal entre os sujeitos, onde estes se vêem a si mesmos como iguais e como diferentes ao mesmo tempo; o espaço legitimado é o plano da validação que dá conta da estabilidade das relações de dominação.

2 A partir de Garrido: 2013, p. 207. Quadro 1: Níveis de produção da experiência espacial elaborado conforme indicação: Baseado em Weber: 1978; Lefebvre: 1991; Fraser e Honneth: 2006 
O quadro abaixo serve de referência na tentativa de fazer um exercício que possibilite ligar o conhecimento do aluno à interpretação da leitura. Nele é possível visualizar a partir dos fragmentos da obra os conceitos de espaço concebido, percebido, vivido, reconhecido e legitimado.

Já o tempo é o objeto da História, mas é impossível falarmos de espaço sem que façamos referência à ele, afinal um inexiste sem o outro. Todo espaço é produzido historicamente, assim como todo tempo tem relação direta com o espaço. Norbert Elias (1998) ao escrever o livro Sobre o Tempo faz referência a um ancião, dizendo que quando não the perguntam sobre o tempo, ele sabe o que é. Quando lhe perguntam, não sabe. É comum que o tempo seja considerado como único, fixo e objetivo.

É preciso que pensemos o tempo em suas diferentes dimensões, dentre elas o tempo físico e o tempo social histórico. O tempo físico, marcado pelo calendário e pelo relógio e pela sucessão das horas, dos dias, dos meses e anos. É definido pela cultura ocidental que inventou um calendário para essas marcações. É imprescindível que façamos a diferenciação com relação ao que Callai (1996) nomina de "tempo social em que a sucessão de fatos e acontecimentos não é regular nem previsível" (p.105). O tempo físico acontece de forma marcada, enquanto o social é construído pelos sujeitos sociais num espaço e em um tempo histórico. É resultado dos movimentos e das transformações considerando diferentes ritmos de tempo e de duração.

Segundo os Parâmetros Curriculares Nacionais para o Ensino Médio:

Os ritmos da duração, conforme descritos por Fernand Braudel, permitem identificar a velocidade em que as mudanças ocorrem e como nos acontecimentos estão inseridas várias temporalidades: a curta duração, a dos acontecimentos breves, com data e lugar determinados; na média duração, no decorrer da qual se dão as conjunturas, tendências políticas e/ou econômicas, que, por sua vez, se inserem em processos de longa duração, com permanências e mudanças que parecem imperceptíveis. É o ritmo das estruturas, tais como a constituição de amplos sistemas produtivos e de relações de trabalho, as formas de organização familiar e dos sistemas religiosos, a constituição de percepções e relações ecológicas estabelecidas na relação entre o homem e a natureza. (Brasil, 1999, p. 25).

O conceito de tempo é extremamente abstrato, pois exige descentração, mas também se apresenta desde o nascimento quase que como algo intrínseco ao sujeito. Inicialmente a criança se relaciona com o tempo subjetivo, pois o vivencia através das rotinas, tanto em casa quanto na escola ou creche. É um processo que ocorre de forma progressiva e muito ligado a ação da criança, como a hora do banho, da mamadeira ou do sono. Tem uma relação direta com necessidades físicas e biológicas, mas não se restringe a elas, pois a cultura vai impregnando nesse sujeito suas marcas. $O$ aluno vive em um tempo e espaço e se relaciona com diferentes espaços e tempos e isso precisa fazer parte do contexto de ensino e aprendizagem desde o início do processo de escolarização.

Os alunos maiores, principalmente os que frequentam as classes do Ensino Médio precisam operar de forma conceitual, realizando a abstração do conceito de tempo. Desta forma, poderão ler de forma intencional, competente e complexa a sociedade contemporânea da qual fazem parte. Poderão exercer a cidadania, pois terão elementos para compreender o processo histórico, ou ainda, seu papel com relação às transformações que esta sociedade necessita. É comum nos romances históricos o ir e vir no tempo. Assim, podemos pensar no tempo histórico como possibilidade de apropriação do conceito e de abstração proporcionados pela literatura que para além dessas questões proporciona possibilidade de ampliação do repertório cultural do sujeito que lê e pensa sobre ele.

Quadro 1

\begin{tabular}{|c|c|c|c|c|}
\hline Espaço concebido & Espaço percebido & Espaço vivido & Espaço reconhecido & Espaço legitimado \\
\hline $\begin{array}{l}\text { "Olhou a catinga amarela, } \\
\text { que o poente vermelhava. Se } \\
\text { a seca chegasse, não ficaria } \\
\text { planta verde". }\end{array}$ & $\begin{array}{l}\text { "Ordinariamente andavam } \\
\text { pouco, mas como haviam } \\
\text { repousado bastante na } \\
\text { areia do rio seco, a viagem } \\
\text { progredira bem três léguas". }\end{array}$ & $\begin{array}{l}\text { "Chegou a porta, olhou } \\
\text { as folhas amarelas da } \\
\text { catingueira. Deus não havia } \\
\text { de permitir outra desgraça. } \\
\text { Agitou a cabeça e procurou } \\
\text { para entreter-se. Tomou a } \\
\text { cuia grande, encaminhou-se } \\
\text { ao barreiro, encheu de } \\
\text { água o caco das galinhas, } \\
\text { endireitou o poleiro. Em } \\
\text { seguida foi ao quintalzinho } \\
\text { regar os craveiros e as } \\
\text { panelas de losna"[...]. }\end{array}$ & $\begin{array}{l}\text { "Agora olhavam as lojas, } \\
\text { as toldas, a mesa de leilão. } \\
\text { E conferiam pasmados. } \\
\text { Tinham percebido que havia } \\
\text { muitas pessoas no mundo. } \\
\text { Ocupava-se em descobrir } \\
\text { uma enorme quantidade } \\
\text { de objetos... O menino teve } \\
\text { uma dúvida e apresentou-a } \\
\text { timidamente ao irmão. Seria } \\
\text { que aquilo tinha sido feito } \\
\text { por gente?" [...]. }\end{array}$ & $\begin{array}{l}\text { "O mulungu do bebedouro } \\
\text { cobria-se de arribações. } \\
\text { Mau sinal, provavelmente o } \\
\text { sertão ia pegar fogo". }\end{array}$ \\
\hline
\end{tabular}

Fonte: elaboração própria a partir dos fragmentos da obra Vidas Secas de Graciliano Ramos. 


\section{O lugar como conceito da geografia e da literatura}

O lugar é um conceito que a geografia trabalha, e se desdobra do conceito de espaço que é o objeto da geografia. Para estudar o lugar não se pode perder de vista o regional, o nacional e o global. Ao assim proceder, supera-se a simples descrição e o tratamento simplificado, pois se torna possível buscar as referências mais amplas que permitem entender o fenômeno em sua dinâmica que é a própria vida. E neste sentido, ao estudar o lugar, os espaços, e os fenômenos ali acontecidos encaminha-se o estudo dos próprios homens, da vida que vivemos.

Isso quer dizer que cada um é sujeito da sua própria vida ou pelo menos que queremos que os alunos sejam capazes de construir a sua identidade e o seu pertencimento, reconhecendo-se como sujeitos cidadãos, que vivem num determinado tempo, no lugar em que estão. Perceber essa dimensão no romance pode levar a desencadear a reflexão a respeito de como os autores daquela história, que embora seja ficção possui relação com a realidade, concebem o mundo da vida. Registramos que nosso objetivo não é usar a obra como parâmetro para estudar geografia, mas para desenvolver a abstração e construir o pensamento a respeito de temas que são significativos para a vida dos sujeitos.

\section{Os conceitos na obra Vidas Secas de Graciliano Ramos}

A obra de Graciliano Ramos retrata a vida e a história do povo nordestino que mesmo sendo ficcional, nos apresenta elementos da realidade vivenciada pelas pessoas desta região. Mesmo que esta realidade tenha sido alterada nas últimas décadas, com diminuição da fome e da miséria, é possível identificar resquícios quando percebemos que a desigualdade social ainda é significativa.

Nossa proposta é que o professor selecione os fragmentos da obra, pois é ele o conhecedor dos conhecimentos teóricos e pedagógicos, bem como, os conceitos que serão trabalhados com os alunos do Ensino Médio. Temos como intenção trabalhar com a observação, a descrição, a análise, a compreensão e a interpretação da obra. É possivel, a partir da obra, identificar em fragmentos a categoria e os conceitos da Geografia. Reforçamos que embora não trabalhado neste texto, que conceitos da Literatura e da História também podem ser explorados, possibilitando assim a interdisciplinaridade. Na sequência, apresentamos um quadro exemplificando como e quais os conceitos da Geografia podem ser trabalhados.

\section{Quadro 2}

Paisagem
"Na planície avermelhada os juazeiros
alargavam duas manchas verdes.
Os infelizes tinham caminhado o dia
inteiro, estavam cansados e famintos.
Ordinariamente andavam pouco, mas
como haviam repousado bastante na areia
do rio seco, a viagem progredira bem três
léguas" [...].

"Olhou a catinga amarela, que o poente avermelhava. Se a seca chegasse, não ficaria planta verde" [...].

"Alcançou o pátio, enxergou a casa baixa e escura, de telhas pretas, deixou atrás os juazeiros, as pedras onde se jogavam cobras mortas, o carro de bois" [...].

"Chegou a porta, olhou as folhas amarelas da catingueira. Deus não havia de permitir outra desgraça. Agitou a cabeça e procurou para entreter-se. Tomou a cuia grande, encaminhou-se ao barreiro, encheu de água o caco das galinhas, endireitou o poleiro. Em seguida foi ao quintalzinho regar os craveiros e as panelas de losna" [...].

Espaço
Espaço relativo:
Ordinariamente andavam pouco,
mas como haviam repousado
bastante na areia do rio seco, a
viagem progredira bem três léguas.
havia de permitir outra desgraça.

\section{Tempo}

Tempo físico:

Os infelizes tinham caminhado o dia inteiro

Tempo social:

Os infelizes tinham caminhado o dia inteiro, estavam cansados e famintos.

Tempo da natureza: A catinga amarela.

Se a seca chegasse, não ficaria planta verde.

Tempo da natureza:

..deixou atrás os juazeiros, as pedras onde se jogavam cobras mortas, o carro de bois...

Ritmos de tempo e de duração:

Chegou a porta..

Em seguida foi ao quintalzinho...

Tempo da natureza:

Olhou as folhas amarelas da catingueira.
Alcançou o pátio, enxergou a casa baixa e escura, de telhas pretas, deixou atrás os juazeiros, as pedras onde se jogavam cobras mortas, o carro de bois.

Em seguida foi ao quintalzinho regar os craveiros e as panelas de losna.
Na planície avermelhada os juazeiros alargavam duas manchas verdes. 


\begin{tabular}{|c|c|c|c|}
\hline Paisagem & Espaço & Tempo & Lugar \\
\hline $\begin{array}{l}\text { "Estava um frio medonho, as goteiras } \\
\text { pingavam lá fora, o vento sacudia os } \\
\text { ramos dascatingueiras, e o barulho do rio } \\
\text { era como um trovão distante" [...]. }\end{array}$ & & $\begin{array}{l}\text { Tempo da natureza: } \\
\text { Estava um frio medonho, as } \\
\text { goteiras pingavam lá fora, o vento } \\
\text { sacudia os ramos das catingueiras. }\end{array}$ & \\
\hline $\begin{array}{l}\text { "Fabiano, sinhá Vitória e os meninos } \\
\text { iam à festa de natal na cidade. Eram três } \\
\text { horas, fazia grande calor, redemoinhos } \\
\text { espalhavam por cima das árvores nuvens } \\
\text { de poeiras e folhas secas" [...]. }\end{array}$ & & $\begin{array}{l}\text { Tempo físico: } \\
\text { Eram três horas, fazia grande calor. } \\
\text { Tempo social: } \\
\text { Fabiano, sinhá Vitória e os } \\
\text { meninos. }\end{array}$ & \\
\hline $\begin{array}{l}\text { "O mulungu do bebedouro cobria-se de } \\
\text { arribações. Mau sinal, provavelmente o } \\
\text { sertão ia pegar fogo" [...]. }\end{array}$ & & $\begin{array}{l}\text { Tempo da natureza: } \\
\text { Provavelmente o sertão } \\
\text { ia pegar fogo. }\end{array}$ & \\
\hline $\begin{array}{l}\text { "Fabiano espiava a catinga amarela, onde } \\
\text { as folhas secas se pulverizavam, trituradas } \\
\text { pelos redemoinhos, e os garranchos se } \\
\text { torciam negros, torrados. No céu azul as } \\
\text { últimas arribações tinham desaparecido. } \\
\text { Pouco a pouco os bichos se finavam, } \\
\text { devorados pelos carrapatos" [...]. }\end{array}$ & $\begin{array}{l}\text { Espaço absoluto: } \\
\text { Fabiano espiava a catinga } \\
\text { amarela, onde as folhas secas se } \\
\text { se pulverizavam, trituradas pelos } \\
\text { redemoinhos, e os garranchos se } \\
\text { torciam negros, torrados. } \\
\text { Espaço relativo: } \\
\text { No céu azul as últimas arribações } \\
\text { tinham desaparecido. }\end{array}$ & $\begin{array}{l}\text { Ritmos de tempo e de duração: } \\
\text { Pouco a pouco os bichos se } \\
\text { finavam, devorados pelos } \\
\text { carrapatos. } \\
\text { Tempo da natureza: } \\
\text { Onde as folhas secas se } \\
\text { pulverizavam... }\end{array}$ & $\begin{array}{l}\text { Fabiano espiava a catinga } \\
\text { amarela, onde as folhas secas se } \\
\text { pulverizavam, trituradas pelos } \\
\text { redemoinhos, e os garranchos se } \\
\text { torciam negros, torrados. No céu } \\
\text { azul as últimas arribações tinham } \\
\text { desaparecido. Pouco a pouco os } \\
\text { bichos sefinavam, devorados pelos } \\
\text { carrapatos. }\end{array}$ \\
\hline
\end{tabular}

Fonte: Elaboração própria a partir dos fragmentos da obra Vidas Secas de Graciliano Ramos.

É possível a partir da categoria de análise paisagem identificar os conceitos de espaço, tempo e lugar na obra literária referida. Desta forma, os alunos e professores das diferentes áreas do conhecimento podem também perceber a relação interdisciplinar entre elas, que não se apresenta de forma forçada, mas articulada. Os conceitos ganham sentido e de certa forma podemos dizer que ocorre a tradução como apontava Marques, pois passam a ser contextualizados.

\section{Considerações finais}

Ensinar geografia no mundo atual, diante das inúmeras demandas que se apresentam na vida dos alunos, é importante pensar alternativas que tornem o ensino possível de gerar aprendizagens que tenham sentido e possam ampliar os conhecimentos que os alunos já possuem. No entanto, é preciso ter claro que não são simples alternativas metodológicas que podem qualificar e dar sentido ao ensino e consequentemente às aprendizagens. Qualquer escolha de metodologia e/ou de encaminhamento do ensino precisa estar fundada em proposição teórica consistente e clara de modo a tornar possível o alcance de bons resultados.
Entendemos que a escola é um lugar onde o aluno vai para aprender e ter acesso ao conhecimento que a humanidade produziu. Por isso, cabe ao professor realizar as ações que possibilitem que os estudantes desenvolvam o pensamento abstrato, que lhes permite entender as questões do mundo. $\mathrm{E}$ isso só pode acontecer através do trabalho com conceitos em que o aluno possa construir tendo os conteúdos como instrumento intelectual para tanto.

A proposição que fazemos de estudar a geografia, considerando a categoria de análise a paisagem e os conceitos de espaço, tempo e lugar a partir de obras literárias pode ser considerada como uma alternativa que auxilie no desenvolvimento do pensamento, fazendo a reflexão, aprendendo os conteúdos. Através da observação, descrição, análise, compreensão e interpretação o exercício desenvolvido a partir da obra Vidas Secas temos os pressupostos para sustentar teoricamente a proposição metodológica que realizamos. Ressaltamos que os conceitos referidos no estudo são básicos na geografia. 


\section{Referências}

Brasil. (1999). Parâmetros Curriculares Nacionais: Ensino Médio. Secretaria de Educação Média e Tecnológica. Brasília: Ministério da Educação.

Callai, H., e Callai, J. (1996). Grupo, espaço e tempo nas séries iniciais. Boletim Gaúcho de geografia, 21(1), 98-108.

Elias, N. (1998). Sobre o tempo. Rio de Janeiro: Jorge Zahar.

Garrido, M. (2013). Conhecer e aprender o espaço: considerações prévias a um processo de interpretação pedagógica. Em L. Cavalcanti (Org.), Temas da Geografia na escola básica (pp.199-217). Campinas, São Paulo: Papirus.

Hermann, N. (2002). Hermenêutica e Educação. Rio de Janeiro: DP\&A.

Moraes, M. (2012). Literatura e espaço: O imaginário em O cortiço e Vidas secas (tese de mestrado). Universidade Regional do Noroeste do Estado do Rio Grande do Sul, ljuí, Brasil.

Marques, M. (2000). Aprendizagem na mediação social do aprendido e da docência. Ijuí: UNIJUI.

Marques, M. (1990). Pedagogia: a ciência do educador. ljuí: UNIJUI.

Ramos, Graciliano (2010). Vidas Secas. Rio de Janeiro: Record.

Santos, M. (1998). Metamorfoses do espaço habitado. São Paulo: HUCITEC.

Silva, A. (1986). De quem é o pedaço? Espaço e Cultura. São Paulo: HUCITEC. 